\title{
Children Adopt the Traits of Characters in a Narrative
}

\author{
Rebecca A. Dore, Eric D. Smith, and Angeline S. Lillard
}

University of Virginia, Charlottesville, VA, USA

Correspondence should be addressed to Rebecca A. Dore; rdore@udel.edu

Received 22 June 2016; Revised 5 December 2016; Accepted 19 December 2016; Published 5 February 2017

Academic Editor: Elena Nicoladis

Copyright (C) 2017 Rebecca A. Dore et al. This is an open access article distributed under the Creative Commons Attribution License, which permits unrestricted use, distribution, and reproduction in any medium, provided the original work is properly cited.

\begin{abstract}
Adults adopt the traits of characters in narratives, but little is known about whether children do so. In Study 1, 7- and 10-year-olds $(N=96)$ heard a 2.5 -minute recording about a professor or cheerleader. Reporting higher engagement in the professor narrative related to more time playing with an analytical toy (a Rubik's cube), whereas reporting higher engagement in the cheerleader narrative related to less time playing with Rubik's cube. However, although children were randomly assigned to a narrative, within condition children may have had preexisting personality differences causing them both to become more engaged in that narrative and also to behave more like that character afterwards. To control for this possibility, in Study 2 children $(N=104)$ were given perspective-taking or objective instructions. Interestingly, both instructions created higher engagement than in Study 1, resulting in main effects of narrative. Children in the professor condition, compared to those in the cheerleader condition, spent more time playing with Rubik's cube and self-reported higher levels of professor-relevant characteristics (e.g., smart, good at teaching). These studies show that, by the elementary school years and particularly when highly engaged in a narrative, children adopt the traits of a narrative's central character.
\end{abstract}

\section{Introduction}

Many parents monitor the books, shows, and movies their children encounter, presumably because they think these narratives influence children beyond the reading or viewing experience: Children who read about a smart or kind character, as opposed to a foolish or rude one, might themselves adopt the protagonists' characteristics. Previous studies have shown that adults do this. In one study, participants who either read a chapter of Harry Potter, a book about wizards, or a chapter of Twilight, a book about vampires, afterwards associated themselves with wizards or vampires, respectively: Participants who read Harry Potter were more likely to answer affirmatively to questions about having the traits and abilities of wizards than participants who read Twilight, and the latter group were more likely to answer affirmatively to questions about having the traits and abilities of vampires [1]. Prior research also suggests perspective taking encourages trait adoption: Adult participants adopted characters' traits to a greater extent when instructed to take the character's perspective [2], when they wrote in first person about a day in the life of a character [3], when they reported becoming more transported into the narrative [4], and when their selfconcept was less accessible [5].

The presence of a similar effect in childhood would have many practical implications. First, it would suggest that parents and teachers may want to consider potentially undesirable traits of the characters in media that children are exposed to and limit that exposure. Such an effect could also be used to promote positive behavior and traits in children. For example, children could be encouraged to be kind or hard-working through engagement with narratives including protagonists with these characteristics. Furthermore, narratives could provide a way to promote healthy behaviors, like exercise and proper nutrition [6]. Thus, an initial study examining whether children adopt characters' traits could lead to further applied research using this concept to have a positive effect on children's lives.

Past research has shown at least one way narratives affect children beyond the reading experience: acquiring new information. For example, 5- to 7-year-olds exposed to short fictional stories containing correct (e.g., "autumn" is another word for "fall") and incorrect facts (e.g., "autumn" is another word for "spring") later reported both forms of facts as 
true [7]. Other research shows that children can learn new information about natural selection and other evolutionary concepts from picture books [8-10]. Furthermore, children learn novel causal facts and problem solutions from storybooks, although story-related factors (i.e., amount of fantasy content) moderate these effects [11-13]. Overall, this research suggests that narratives can have an effect on children but leaves open the question of whether children might adopt the traits of characters in a narrative in addition to learning new information from narratives.

One reason children may not adopt the traits of characters is that their perspective-taking skills are underdeveloped, relative to those of adults $[14,15]$. Research also shows perspective taking improves across middle childhood. Given the relationship between perspective-taking and narrative effects on adults, this suggests that trait adoption from narratives might occur only in older children, whose perspective-taking skills are more similar to adults, but not in younger children [14-16].

On the other hand, absorption in a narrative might be facilitated by the same features that enable children to engage in pretend play. Pretend play is a distinguishing feature of both early [17] and middle childhood, with research showing that children engage in pretend play until 11 years of age on average [18]. To the extent that engagement in narratives is an extension of children's pretense (possibly because both experiences involve imagining the world from someone else's point of view [19]), children may be more likely than adults to become intensely absorbed in narratives and, in line with research with adults $[4,5,20]$, may be more likely to be affected by these experiences. Unfortunately, very little research to date has examined school-age children's involvement in narratives. In the current studies, we included both 7and 10-year-old participants in order to test an early- versus later-developing effect of narratives on children's adoption of characters' traits. However, we predict that children of both ages will show the effect, given children's involvement in pretense and findings that young children experience a narrative from the perspective of the protagonist [21-23].

One recent study may indirectly shed light on this issue and suggest that even preschoolers adopt characters' traits: Lee et al. [24] found the story of George Washington and the cherry tree, which focuses on the positive consequences of honesty, promoted honesty immediately thereafter in 3to 7-year-olds relative to stories focusing on the negative consequences of dishonesty, namely, The Boy Who Cried Wolf and Pinocchio. These results were interpreted as showing children are influenced by the consequences of the character's actions. However, given that the lying behavior also differs across stories, it seems feasible that the results reflect trait adoption instead. Specifically, the George Washington story has positive consequences and the character in the story behaves honestly. Thus, it seems feasible that children were adopting the character's trait of honesty, regardless of consequences. Further research is needed to disentangle these explanations.

"Traits" herein refer to "distinguished qualities or characteristics belonging to one person," namely, a narrative's protagonist. Our interest is in how reading about this protagonist might temporarily affect one's self-beliefs, behaviors, and cognitions. For example, viewing a character who is kind could cause a child to think about him/herself as more kind, to behave more kindly, and to think more kind thoughts. Although these possible effects (self-beliefs, behaviors, and cognition) may be separable, they have been treated as one construct in past research with adults [2-4] and will be considered together here. We do, however, distinguish between two possible types of effects on a different dimension: explicit effects, measured by self-ratings, and implicit effects, measured by behaviors.

The current research adapted the basic paradigm Galinsky et al. [2] used with adults to examine whether children adopt the stereotypical traits of a professor and a cheerleader following a narrative. Based on studies with adults [1-5] we hypothesized that both explicit and implicit effects will be apparent. On an explicit or self-report level, we expected that children who heard a narrative about a professor would see themselves as smarter and better at professor-relevant behaviors, whereas children who heard a narrative about a cheerleader would see themselves as more attractive and better at cheerleader-relevant behaviors. On an implicit or behavioral level, given the stereotypes that professors are smart and analytical and cheerleaders are unintelligent, we expected children who heard the professor narrative would spend more time playing with an analytical toy and would perform better on a measure of analytical reasoning, compared to children who hear a narrative about a cheerleader.

As noted above, previous research has found that adults adopt characters' traits to a greater extent when instructed to take the character's perspective [2], when they wrote in first person about a day in the life of a character [3], when they reported becoming more transported into the narrative [4], and when their self-concept was less accessible [5]. These findings suggest that some form of engagement with the narrative may promote trait adoption in children as well. Although perspective taking, narrative transportation, and related constructs like identification may be theoretically distinct; even in the adult literature their definitions and measurement are unclear (see [25]). Fully explicating the distinctions between these concepts is beyond the scope of the current research. We do, however, provide detailed analyses of these measures to (1) show how the adapted measures behave and interrelate in a child sample and (2) assess their relation to trait adoption effects. Based on the adult research showing that trait adoption is related to the extent to which individuals are engaged in a narrative [25], we hypothesized that more engaged children would more strongly adopt protagonists' traits. That is, engagement will be positively related to adopting the traits of the cheerleader for children who heard the cheerleader narrative but not for those who heard the professor narrative. On the other hand, engagement will be positively related to adopting the traits of the professor for children who heard the professor narrative but not those who heard the cheerleader narrative.

Participants of 7 and 11 years of age were used because they are at the beginning and end of elementary school, thus allowing us to explore whether any effects of the narrative are consistent across middle childhood. Age 7 was also thought 
to be the earliest age at which one could meaningfully selfreport level of engagement in the narrative. Theory of mind improves across this time period [14-16] and if these more advanced mentalizing skills are necessary for trait adoption, we might expect 10-year-olds, but not 7-year-olds, to show effects of the narrative. However, given evidence that even young children take the physical perspective of protagonists in narratives [21-23] and may also adopt their moral traits [24], it seemed possible that even 7-year-olds would adopt the characters' traits. We also examine results by gender in order to rule out the possibility that a child's gender influences their adoption of a character's traits.

In sum, the primary objectives of Study 1 are to assess (1) whether children, like adults, will adopt the traits of a character in a narrative, (2) whether children's trait adoption is related to their engagement, and (3) whether this effect differs by child age or gender. A secondary, more exploratory, goal of Study 1 is to adapt narrative engagement measures for use with children and assess the behavior of these measures and their interrelations.

\section{Study 1}

\subsection{Method}

2.1.1. Participants. Participants were 96 children, 48 sevenyear-olds (24 girls, $M=7 ; 6$, range: $7 ; 0-8 ; 0$ ) and 48 ten-yearolds (24 girls, $M=10 ; 6$, range: $10 ; 0-11 ; 1)$. Ten additional children were tested but excluded from analyses: 3 due to technical difficulties, 4 because they were distracted or uncooperative, 1 for not demonstrating sufficient understanding of a key measurement technique (visual analogue scale), and 2 for demonstrating insufficient memory for the narrative. Children were drawn from a database of families willing to bring their children to the laboratory to participate in research and were primarily White and middle to uppermiddle class, reflecting the composition of local families who volunteer for research.

2.1.2. Procedure and Materials. Children were randomly assigned to hear the professor or cheerleader narrative with the constraint that equal numbers of 7 - and 10 -year-olds boys and girls heard each story (i.e., 12 children in each of 8 age group/gender/narrative cells). After listening to the narrative, children completed a filler task. Next, children completed two explicit (trait and ability self-ratings) and two implicit (toychoice and analytical reasoning) measures of trait adoption. Children were then given four measures of engagement (the adapted Narrative Transportation Scale [20], perceived similarity, wishful identification, and a direct measure of identification). Finally, children's memory for the narrative was assessed through free recall, followed by specific questions. Memory measures were included to ensure that children paid attention to and processed the story. Children who did not demonstrate sufficient memory for the narrative were excluded from analyses, given our expectation that processing a story is required for it to have effects.

Narrative. Children heard a 2.5-minute recording of the character describing a typical day in his/her life; scripts are in Appendix A. The script for the professor recording was adapted from Galinsky et al. [2] for use with children and depicts a middle-aged adult male describing his day, including teaching, working on research, and writing a book review. The script for the cheerleader recording was created for this study and depicts a teenage female describing her day, including picking out a school outfit, being bored in class, and attending cheerleading practice. The cheerleader recording was matched to the professor recording on word count, timing, and reading level (Flesch-Kincaid Grade Level scores $=7.6)$ and, to the extent possible, on narrative structure and content. Children listened to recordings using an iPod with headphones, and a photograph described as depicting the character was positioned on the table in front of them.

Filler Task. After the recording, children were asked to draw a picture of a house for 5 minutes, in line with Galinsky et al. [2] in which participants completed a brief filler task after narrative exposure and prior to the dependent variables.

Visual Analogue Scale Training. Prior to using visual analogue scales to respond to the primary measures, children were trained to use the scale using a $10 \mathrm{~cm}$ line with the words black and white at the endpoints. They were then shown a series of shaded squares (black, white, gray, light gray, and dark gray, in that order) and asked to mark on the line where each square should go. Responses were marked correct if the squares were placed in relative order of darkness on the line. Incorrect responses were corrected; 14 children responded incorrectly on one of five training items, one child responded incorrectly on three items. One additional child did not demonstrate understanding of the scale after being corrected; this child was excluded from further analyses.

Explicit Measures. Children responded to all rating items (ability and trait self-ratings and narrative engagement measures) using visual analogue scales, following other studies in which researchers aimed to minimize constraints on children's responses [26]. To respond to each item, children made a mark on a $10 \mathrm{~cm}$ line with not at all and very as the endpoints. This line was described as being "sort of like" the line children used in training and the new endpoints were explained. Responses were coded by measuring how far the child's mark was from the left endpoint of the line (not at all), with a possible range of 0 to 10 .

Children completed ability and trait self-ratings, counterbalanced. For ability self-ratings, children were told to mark on the line to indicate how good they were at some different things. Children responded to three items relevant to the cheerleader (e.g., "How good are you at shouting loudly?"), three items relevant to the professor (e.g., "How good are you at teaching other people?"), and six irrelevant distractor items (e.g., "How good are you at setting the table?"). These items were presented to all children in one random order, with no two items relevant to either character presented sequentially.

For trait self-ratings, children were told to mark on the line to indicate how well some different words described them. The first two items were relevant to the professor and 
cheerleader character, respectively: "smart" and "pretty or handsome," counterbalanced to test for order effects. After these items, children responded to seven distractor items (e.g., "hungry" and "adventurous") placed after the targets to ensure distractors did not affect responses on the targets (see Appendix B).

Although Galinsky et al. [2] used multiple items for each character in their study with adults, piloting showed that children did not consistently know definitions of synonyms and related words (i.e., attractive, intelligent). In addition, studying children necessitates shorter procedures than can be used with adults. To ameliorate psychometric concerns about relying on a smaller set of individual items to capture the dependent variables, responses on the "smart" trait rating item and the three professor-relevant ability-rating items, each with a possible range of 0 to 10 , were summed to create a professor composite score, and responses on the "pretty or handsome" trait rating item and the three cheerleaderrelevant ability-rating items were summed to create a cheerleader composite score. Thus, each composite could range from 0 to 40, with higher scores indicating higher adoption of that character's traits.

Implicit Measures. After the explicit measures, children completed two implicit measures: a toy-choice task and an analytical reasoning task. These measures were chosen as an analogue to the analytical reasoning measure used by Galinsky and colleagues [2] with adults, which was comprised of questions from the analytical reasoning section of the Law School Admission Test (LSAT). Although we did not expect children's actual analytical abilities to permanently change as a result of narrative exposure, we hypothesized (based on adult studies) that children who heard the professor narrative might change in their performance. One can speculate as to possible reasons for this, for example, interest and motivation inspired by the narrative.

In the toy-choice task, the experimenter left the room under the pretense of retrieving something for the study. Before leaving, she told children, "There are a couple of toys on the table over there if you want something to do while I'm gone," pointing to a Rubik's cube (the analytical toy) and a yoyo (the nonanalytical toy) on a small table. These particular toys were chosen because playing with a Rubik's cube requires analytical thinking skills, whereas playing with a yo-yo does not. Children's behavior was coded from video for time spent playing with each toy out of a possible 5 minutes. A second coder, blind to condition and hypotheses, coded $20 \%$ of the data. Agreement was excellent for time playing with Rubik's cube $($ ICC $=.998)$ and the yo-yo $($ ICC $=.986)$.

Children then completed the matrix reasoning subtest of the Wechsler Intelligence Scale for Children (WISC) [27] as a measure of analytical reasoning skills. Children respond to items until they respond incorrectly to four of five consecutive items. Scaled scores accounting for child age were used in analyses.

Engagement Measures. To assess children's perspective taking and narrative engagement, we administered the following four measures:
(1) Narrative Transportation Scale (9 items; adapted from [20])

(2) Perceived similarity: "How similar do you think you are to the person in the recording?"

(3) Wishful identification: "How much do you want to be like the person in the recording?" [28]

(4) Direct measure of identification: "Sometimes when you hear a story you actually see yourself as the person in the story. In a funny sort of way, you become the other person. Did you see yourself as the person in the recording or not?" [29]

Children responded to all engagement measures using visual analogue scales with not at all and very as the endpoints. Responses were coded by measuring how far the child's mark was from the left endpoint of the line (not at all), with a possible range of 0 to 10 .

The adapted Narrative Transportation Scale [20] included nine items, three of which were reverse scored. Children were told to mark on the line to indicate how much they agreed with different sentences about listening to the recording. Items assessed narrative absorption (e.g., "While you were listening to the recording, you could easily picture the events happening"; see Appendix C).

Memory Measures. To assess memory for the recording, children were asked to freely recall the recording they heard. Free recall was coded by indicating how many of a predetermined set of possible details children recalled from the narrative. In addition to the total number of details recalled, the number of character-relevant details recalled was also recorded, but results did not differ so results are described only for total details.

After the free recall period, children were asked eight open-ended memory questions about specific events or descriptions from the recordings. Five questions were the same for the two narratives (e.g." "Who did he/she have lunch with?"); three questions asked about parallel sections of the narrative but were necessarily different for the two recordings (e.g., "Why did he want to do good research?" "Why did she want to be a good cheerleader?"). Responses were coded as correct or incorrect and summed; total scores could range from 0 to 8 . Two children were excluded from the analyses because they failed to remember any details on free recall and answered fewer than 3 questions correctly.

2.2. Results. First, we present preliminary analyses, including (1) internal consistency of the first engagement measure, the adapted Narrative Transportation Scale, (2) differences on all four engagement measures by age group, gender, and narrative, (3) the relationships between the four measures of engagement, and (4) the relationship between engagement and memory. Next, we consider the primary analyses pertaining to main effects of narrative and narrative $x$ engagement interactions, showing whether children adopted the traits of the characters. For descriptive statistics for trait adoption measures, see Table 1. For descriptive statistics for the engagement and memory measures, see Table 2 . 
TABLE 1: Descriptive statistics for trait adoption measures in Study 1 .

\begin{tabular}{lc}
\hline & Mean (SD) \\
\hline $\begin{array}{l}\text { Professor behavior/trait composite } \\
\text { (possible range: 0-40) }\end{array}$ & $28.2(6.4)$ \\
$\begin{array}{l}\text { Cheerleader behavior/trait composite } \\
\text { (possible range 0-40) }\end{array}$ & $24.7(6.1)$ \\
$\begin{array}{l}\text { Time playing with Rubik's cube } \\
\text { (in seconds; possible range: 0-300) }\end{array}$ & $162.1(100.0)$ \\
$\begin{array}{l}\text { Time playing with yo-yo } \\
\text { (in seconds; possible range 0-300) }\end{array}$ & $77.2(78.9)$ \\
$\begin{array}{l}\text { WISC matrix reasoning scaled score } \\
\text { (possible range: 0-35) }\end{array}$ & $11.4(3.4)$ \\
\hline
\end{tabular}

TABLE 2: Descriptive statistics for engagement and memory measures in Study 1.

\begin{tabular}{lc}
\hline & Mean (SD) \\
\hline Become (direct identification) & $2.5(3.2)$ \\
Narrative transportation & $49.5(13.9)$ \\
Perceived similarity & $2.4(2.6)$ \\
Wishful identification & $3.2(3.2)$ \\
Free recall-total components & $8.8(4.6)$ \\
Memory questions & $4.6(1.8)$ \\
\hline
\end{tabular}

2.2.1. Preliminary Analyses. Adapted Narrative Transportation Scale. The full 9-item adapted Narrative Transportation Scale had a Cronbach's alpha of .63. Dropping Item \#2 (see Appendix C) improved the alpha to .70. Removing other items did not further improve the alpha. Principal components analysis using varimax rotation showed the remaining eight items loaded onto one factor, accounting for $34 \%$ of the variance. These eight items were summed to create a narrative transportation score, with a possible range of 0 to 80 .

Engagement Measures. Regression analyses revealed no main effects of or interactions between age group and narrative on narrative transportation. However, there were significant results for the other three engagement measures. Seven-yearolds reported being more similar to the cheerleader $(M=3.0$, $\mathrm{SD}=3.1)$ than to the professor $(\mathrm{M}=1.7, \mathrm{SD}=2.4)$, whereas 10 -year-olds reported being more similar to the professor $(\mathrm{M}$ $=3.0, \mathrm{SD}=2.4)$ than to the cheerleader $(\mathrm{M}=2.0, \mathrm{SD}=2.3)$, $B=2.25, p=.035$, and $s p^{2}=.048$. Similarly, 7-year-olds reported wanting to be like the cheerleader $(\mathrm{M}=4.6, \mathrm{SD}=$ 4.2) more than the professor $(\mathrm{M}=2.7, \mathrm{SD}=3.4)$, whereas 10 -year-olds reported wanting to be like the professor $(\mathrm{M}=$ 3.8, $\mathrm{SD}=2.3)$ more than the cheerleader $(\mathrm{M}=2.0, \mathrm{SD}=$ 2.2), $B=3.75, p=.004$, and $s p^{2}=.086$. There was no age group $\times$ narrative interaction for the direct measure of identification ("Did you see yourself as the person in the recording or not?"). Instead, across both age groups, children reported higher identification in the cheerleader $(\mathrm{M}=3.2, \mathrm{SD}$ $=3.6)$ than in the professor narrative $(\mathrm{M}=1.9, \mathrm{SD}=2.7), t(87)$ $=2.1$ and $p=.035$.

Across all four engagement measures, controlling for narrative, girls reported higher engagement than boys, as follows: narrative transportation (girls: $\mathrm{M}=53.4, \mathrm{SD}=12.0$; boys: $\mathrm{M}=45.7, \mathrm{SD}=14.6 ; B=7.6, p=.007$, and $s p^{2}=.076$ ); perceived similarity (girls: $\mathrm{M}=3.2, \mathrm{SD}=2.7$; boys: $\mathrm{M}=1.7$, $\mathrm{SD}=2.2 ; B=1.51, p=.004$, and $\left.s p^{2}=.086\right)$; wishful identification (girls: $\mathrm{M}=3.9, \mathrm{SD}=3.3$; boys: $\mathrm{M}=2.6, \mathrm{SD}=3.1$; $B=1.31, p=.048$, and $\left.s p^{2}=.042\right)$; and direct identification (girls: $\mathrm{M}=3.1, \mathrm{SD}=3.4$; boys: $\mathrm{M}=2.0, \mathrm{SD}=3.0 ; B=0.34$, $p=.09$, and $\left.s p^{2}=.029\right)$. There were no gender $\times$ narrative interactions.

Relationship between Engagement Measures. The four engagement measures were intercorrelated, $r s>.21$ and $p s<.05$ (see Appendix D). Principal components analysis using varimax rotation showed one factor explained $52 \%$ of the variance, and all variables had high loadings on the first component (all loadings $>$.62). Thus, an engagement composite was created by standardizing and summing the four engagement measures; this composite score was used in the primary analyses.

Memory Measures. The two measures of memory were intercorrelated $(r=.60, p<.0001)$. However, neither measure related to any of the engagement measures ( $p s>.38$ ), nor was a standardized sum of the measures related to the engagement composite, $p=.66$.

2.2.2. Primary Analyses. Regression models informed whether children adopted the traits of the characters. Models were estimated using the function $\mathrm{lm}$ in the $\mathrm{R}$ software environment [30]. The initial models predicted each dependent variable from narrative (professor or cheerleader), the engagement composite, and the interaction between narrative and engagement composite. Nonsignificant predictors were systematically removed using model comparison (Akaike information criterion, a measure of the relative goodness of fit; see [31]). Controlling for gender and age group in each model did not change the pattern of results, so models without these variables are described here. Where significant interactions between narrative and engagement composite emerged, three-way interactions with gender and age group were tested to ensure that engagement in the narrative did not affect boys' and girls' and 7- and 10-yearolds' behavior differentially. Null results in these analyses demonstrated that effects were similar across genders and age groups.

Explicit Measures. Children's explicit adoption of characters' traits was measured using self-ratings of professorand cheerleader-related traits and behaviors. There were no meaningful effects of either task order or item order and neither interacted with the effects of narrative. Regression analyses also indicated there were no significant effects of narrative or interactions between narrative and engagement (professor composite: interaction $B=.24, \mathrm{SE}=.47, p=.62$, $s r^{2}=.003$, model $r^{2}=.06$, narrative $B=0.35, \mathrm{SE}=1.3$, $p=.79$, and engagement $B=.43, \mathrm{SE}=.29, p=.13$; cheerleader composite: interaction $B=-0.3, \mathrm{SE}=0.4, p=.46$, $s r^{2}=.005, r^{2}=.18$, narrative $B=-0.53, \mathrm{SE}=0.8$, 


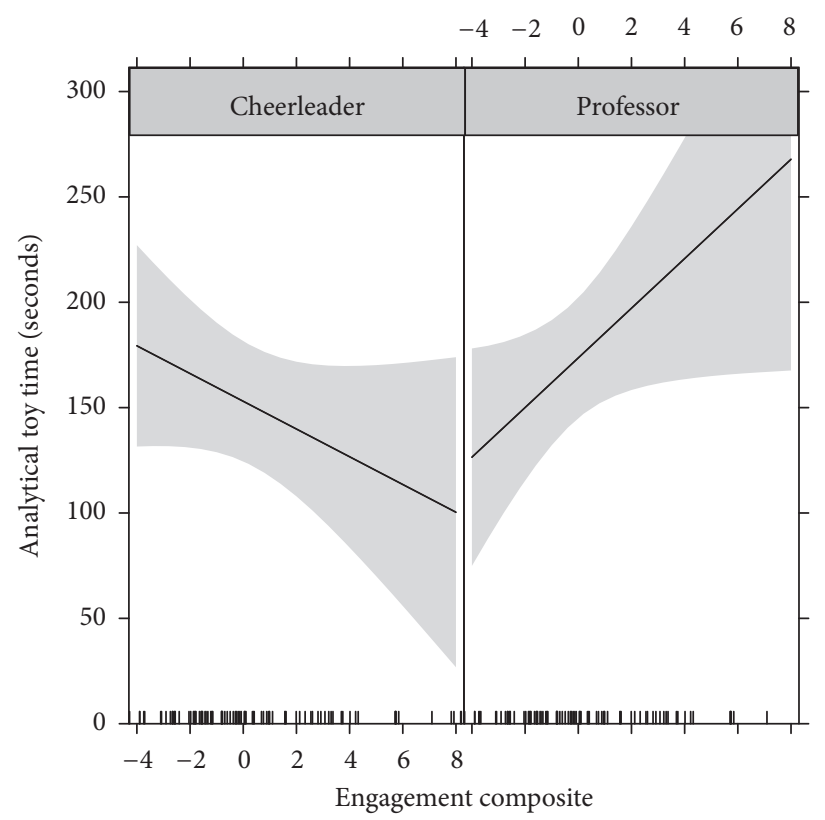

(a)

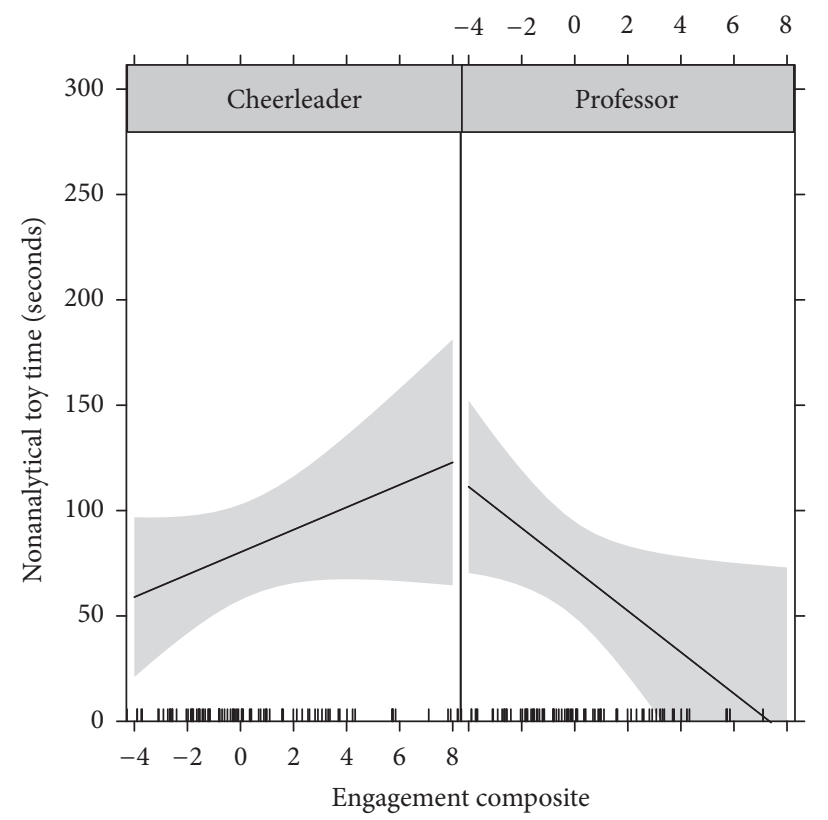

(b)

FIGURE 1: Effect of engagement composite on time spent playing with the analytical toy, a Rubik's cube (a), and the nonanalytical toy, a yo-yo (b), in Study 1. Note: shading represents $95 \%$ confidence intervals.

$p=.64$, and engagement $B=1.0, \mathrm{SE}=.25, p<.001)$. Thus, narrative exposure did not influence children's explicit responses in rating their own professor-like or cheerleaderlike characteristics.

Implicit Measures. There were significant interactions between narrative and engagement on one of the implicit measures. Specifically, there was a significant narrative $x$ engagement interaction predicting time spent playing with the analytical and nonanalytical toys. Among children who heard the professor narrative, the engagement composite was related to more time playing with Rubik's cube, whereas, among children who heard the cheerleader narrative, the engagement composite was related to less time playing with Rubik's cube, interaction $B=18.4, \mathrm{SE}=7.3, p=.01$, and $s r^{2}=.06$, model $r^{2}=.07$, narrative $B=20.6, \mathrm{SE}=20.3$, and $p=.31$, and engagement $B=-6.6, \mathrm{SE}=4.5$, and $p=.14$. Correspondingly, among children who heard the cheerleader narrative, the engagement composite was related to more time playing with the yo-yo, whereas, among children who heard the professor narrative, the engagement composite was related to less time playing with the yo-yo, interaction $B=-15.1, \mathrm{SE}=5.8, p=.01$, and $s r^{2}=.07$, model $r^{2}=.07$ (see Figure 1), narrative $B=-8.2, \mathrm{SE}=16.1$, and $p=.61$, and engagement $B=5.3, \mathrm{SE}=3.5$, and $p=.14$. Note time spent playing with the nonanalytical toy is not a direct inverse of the time spent playing with the analytical toy, because children were not always playing with a toy. There were no main effects of narrative on time spent playing with either toy. This result suggests children's trait adoption was contingent upon the extent to which they were engaged in the narrative.

Regression analyses indicated there were no significant effects of narrative or interactions between narrative and engagement on the second implicit measure-the WISC analytical reasoning score, interaction $B=0.2, \mathrm{SE}=.26$, $p=.55, s r^{2}=.004$, and $r^{2}=.008$; narrative $B=-0.5, \mathrm{SE}=$ .71 , and $p=.49$; engagement $B=-0.21, \mathrm{SE}=.16$, and $p=.17$, suggesting that children's analytical reasoning skills were not affected by their engagement with the narratives.

2.3. Discussion. In this study, children adopted characters' traits, at least on an implicit level, to the extent they were engaged with the narrative. Among children who heard the professor narrative, those who reported higher engagement spent more time playing with an analytical toy and spent less time playing with a nonanalytical toy. On the other hand, among children who heard the cheerleader narrative, those who reported higher engagement spent more time playing with the nonanalytical toy and spent less time playing with the analytical toy. Inclusion of the cheerleader narratives provides an important control because it allows us to rule out the possibility that increased engagement in any narrative leads to behaving more analytically. Rather, the effect is confined to stereotypical traits associated with the particular character.

However, our method of measuring rather than manipulating perspective taking leaves open an alternative interpretation: Although children were randomly assigned to a narrative, within condition children may have had preexisting personality differences causing them both to become more engaged in that narrative and also to behave more like that character afterwards. To examine this possibility, in Study 2, we attempted to manipulate perspective taking by instructing children to take the character's perspective or to be objective. Specifically, we adapted instructions used with adults to be comprehensible to children and used manipulation checks to assess understanding. 


\section{Study 2}

The primary objective of Study 2 was to assess whether children adopt the traits of a character in a narrative only when highly engaged (after being given perspective-taking instructions) and not when less engaged (after being given instructions to remain objective). Based on past research [2], we hypothesized that children would adopt the traits of a character after hearing the perspective-taking instructions but not after hearing the objective instructions. Following from Study 1, a secondary goal was to further examine the use of narrative engagement measures with children.

\subsection{Method}

3.1.1. Participants. Participants were 105 children, 57 sevenyear-olds (31 girls, $M=7 ; 6$, range: $7 ; 0-8 ; 0$ ) and 48 ten-year-olds ( 23 girls, $M=10 ; 6$ and range: $10 ; 1-11 ; 0)$. (More 7- than 10-year-olds were run because we originally planned to exclude children who failed the instructions comprehension check [described below] but did not do so when analyses showed their key results were no different from those of children who passed. This also led to an uneven number of children of each gender and age group assigned to each condition. Excluding these children, boys and girls are approximately evenly divided between conditions [i.e., \pm 1 ] but because exclusion did not change the pattern of the data, the full sample is included in the analyses described here. The full sample included 21 seven-year-olds in the objective instructions/cheerleader narrative condition, 13 seven-year-olds in the objective instructions/professor narrative condition, 12 seven-year-olds in the perspectivetaking instructions/cheerleader narrative condition, 11 sevenyear-olds in the perspective-taking instructions/professor narrative condition, 12 ten-year-olds in the objective instructions/cheerleader narrative condition, 11 ten-year-olds in the objective instructions/professor narrative condition, 12 tenyear-olds in the perspective-taking instructions/cheerleader narrative condition, and 12 ten-year-olds in the perspectivetaking instructions/professor narrative condition.) Three additional children were tested but excluded from analyses, one for uneasiness being in the testing room alone and two due to insufficient memory for the narrative. Recruitment and other sample demographics aligned with Study 1.

3.1.2. Procedure. Children were randomly assigned to (1) receive either perspective-taking or objective instructions and (2) hear either the professor or cheerleader narrative. Children heard instructions immediately prior to listening to the narrative and completing the trait adoption tasks. Because there were no meaningful effects of task order and item order in Study 1, one static order was used: the ability-rating task was administered before the trait rating task, and the "smart" item was administered before the "pretty or handsome" item. After the trait adoption tasks, children responded to engagement measures. Immediately following the engagement measures, three manipulation check questions probed whether children reported following the instructions. Then, children's memory for the narrative was assessed. Finally, children's comprehension of the instructions was assessed through an open-ended question. Aspects of the procedure unique to Study 2 are described below.

Instructions. Children were told they would listen to a short recording about a person describing a typical day in his/her life. Then children heard either perspective-taking or objective instructions, adapted from Galinsky et al. [2] as follows.

Perspective-Taking. "Now I'm going to tell you something really important. While you listen to this story, I want you to take the perspective of the person in the story. Imagine what it would be like to be this person. Try to imagine what you would feel and think if you were that person. Try to go through the day in the life of this person as if you were that person. Try as hard as you can to clearly picture the events happening. Don't worry about trying to remember everything that happens. Just imagine what you would feel if you were that person going through his/her day."

Objective. "Now I'm going to tell you something really important. While you listen to this story, I want you to think about yourself as someone who is just hearing about the person and the events in the story. Try to remember that you are hearing about what is happening to this person and what their day is like from the outside. Don't worry about trying to imagine what this person's life is like, how the person feels, or what it would be like to be this person. Just listen to the story and remember that you are an outsider, only hearing about what is happening."

Manipulation Check. After the engagement measures (see Study 1), children answered three questions assessing the extent they reported engaging in the behaviors indicated in the instructions: (1) "How much did you take the perspective of the person in the story?" (2) "How much did you imagine what it would be like to be the person in the story?" and (3) "How much did you imagine what the person in the story was thinking and feeling?"

Instructions Comprehension Check. To assess whether children understood the instructions, at the end of the procedure the experimenter asked children, "Remember, before you listened to that recording earlier, I told you to do something. Can you tell me what you supposed to be doing while you listened to the recording?" Responses were coded as correct or incorrect based on whether they accurately represented the intentions behind the perspective-taking or objective instructions. To examine coding reliability, a second coder coded $20 \%$ of the data; agreement was $100 \%$.

Toy-Choice Task. The same toy-choice task was used as in Study 1. To examine reliability, a second coder, blind to condition and hypotheses, coded $20 \%$ of the data. Agreement between the two raters was excellent for time playing with Rubik's cube $($ ICC $=.990)$ and yo-yo $($ ICC $=.994)$.

3.2. Results. The analyses below mainly follow Study 1 but begin with analyses related to the manipulation checks 
TABLE 3: Descriptive statistics for trait adoption measures in Study 2.

\begin{tabular}{lc}
\hline & Mean (SD) \\
\hline $\begin{array}{l}\text { Professor behavior/trait composite } \\
\text { (possible range: 0-40) }\end{array}$ & $29.3(6.6)$ \\
$\begin{array}{l}\text { Cheerleader behavior/trait composite } \\
\text { (possible range 0-40) }\end{array}$ & $24.5(6.9)$ \\
$\begin{array}{l}\text { Time playing with Rubik's cube } \\
\text { (in seconds; possible range: 0-300) }\end{array}$ & $155.6(93.6)$ \\
$\begin{array}{l}\text { Time playing with yo-yo } \\
\text { (in seconds; possible range 0-300) }\end{array}$ & $109.7(87.6)$ \\
$\begin{array}{l}\text { WISC matrix reasoning scaled score } \\
\text { (possible range: 0-35) }\end{array}$ & $11.9(3.0)$ \\
\hline
\end{tabular}

Note: means are collapsed across instructions conditions, because no significant differences were observed.

and instructions comprehension and end with comparative analyses of whether engagement and memory differed between Studies 1 and 2. Descriptive statistics for trait adoption measures are provided in Table 3; information on the engagement and memory measures including comparisons to Study 1 is given in Table 4 .

3.2.1. Preliminary Analyses. Manipulation Checks. Instructions affected children's performance on the manipulation check items (see Table 4). Children instructed to take the character's perspective reported imagining what it would be like to be the person in the story to a greater extent ( $M$ $=6.8, \mathrm{SD}=2.8)$ than children instructed to be objective $(\mathrm{M}=5.6, \mathrm{SD}=3.6), t(103)=1.98, p=.05$, and $d=$ .38. Similarly, children instructed to take the character's perspective reported imagining the character's thoughts and feelings to a greater extent $(\mathrm{M}=7.4, \mathrm{SD}=2.3)$ than children instructed to be objective $(\mathrm{M}=5.7, \mathrm{SD}=3.6), t(98)=3.12$, $p=.002$, and $d=.58$. Ten-year-olds, but not 7-yearolds, also showed an effect of instructions for the item asking how much one took the character's perspective: 10 -year-olds reported taking the character's perspective to a greater extent after the perspective-taking instructions $(\mathrm{M}=7.4, \mathrm{SD}=1.6)$ compared to the objective instructions $(\mathrm{M}=5.9, \mathrm{SD}=2.8)$, $t(37)=2.2, p=.03$, and $d=.68$. It appeared 7-yearolds did not understand this question, indicated by 28 out of 57 seven-year-olds asking the experimenter what the word "perspective" meant before responding, whereas only 4 out of 47 ten-year-olds did so.

Instructions did not affect children's responses on three engagement measures: narrative transportation, perceived similarity, and the direct measure of identification. There was an unexpected effect of instructions on wishful identification, showing children wanted to be like the character more after hearing objective instructions $(\mathrm{M}=4.0, \mathrm{SD}=3.7)$ than after hearing perspective-taking instructions $(\mathrm{M}=2.7, \mathrm{SD}=2.5)$, $t(101)=-2.2, p=.03$, and $d=.42$.

Instructions Comprehension. A significant number of children, particularly 7-year-olds who received objective instructions, did not pass the comprehension check. Specifically, 21 out of these 34 children were unable to describe what they had been told to do while listening to the recording. Additionally, 7 out of 23 seven-year-olds who received perspectivetaking instructions, 7 out of 23 ten-year-olds who received objective instructions, and 2 out of 24 ten-year-olds who received perspective-taking instructions failed the comprehension check. Excluding these children from analyses did not change the pattern of results, so their data is included here.

Adapted Narrative Transportation Scale. The full 9-item adapted Narrative Transportation Scale had a Cronbach's alpha of .54. Dropping Items \#2, \#6, and \#7 (see Appendix C) improved the alpha to .62. Removing other items did not improve the alpha. Principal components analysis using varimax rotation showed the remaining six items all loaded onto one factor, accounting for $38 \%$ of the variance. These six items were summed to create a narrative transportation score, with a possible range of 0 to 60 .

Engagement Measures. In predicting narrative transportation, there was no interaction between narrative and age group, but there was a main effect of age group: 10 -year-olds $(\mathrm{M}=44.0$, $\mathrm{SD}=10.9)$ reported higher narrative transportation than 7year-olds $(\mathrm{M}=39.5, \mathrm{SD}=9.6), t(92)=2.22, p=.03$, and $d=.44$. There were no main effects of narrative, gender, or interactions between narrative and gender; boys and girls reported similar levels of transportation after hearing the cheerleader and professor narratives.

As in Study 1, 7- and 10-year-olds differed in their wishful identification with the characters: 7-year-olds reported wanting to be like the cheerleader $(\mathrm{M}=4.7, \mathrm{SD}=3.9)$ more than the professor $(\mathrm{M}=2.7, \mathrm{SD}=2.8)$, whereas 10-year-olds reported wanting to be like the professor $(\mathrm{M}=3.6, \mathrm{SD}=2.7)$ more than the cheerleader $(\mathrm{M}=2.1, \mathrm{SD}=2.6), B=3.54, p=.005$, and $s p^{2}=.07$. There was also a gender $\times$ narrative interaction showing girls reported wanting to be like the cheerleader $(\mathrm{M}$ $=5.1, \mathrm{SD}=3.8)$ more than the professor $(\mathrm{M}=2.8, \mathrm{SD}=2.8)$, whereas boys reported wanting to be like the professor $(\mathrm{M}=$ $3.4, \mathrm{SD}=2.8)$ more than the cheerleader $(\mathrm{M}=1.7, \mathrm{SD}=2.5)$, $B=-3.94, p=.001$, and $s p^{2}=.09$.

There were no effects of age group or gender or interactions between these variables and narrative on perceived similarity or the direct measure of identification.

Relationship between Engagement Measures and with Manipulation Check Items. Three engagement measures (perceived similarity, wishful identification, and the direct measure of identification) were intercorrelated, $r s>.26$ and $p s<.006$. Narrative transportation related only to the direct measure of identification, $r=.36$ and $p=.0002$ (see Appendix E).

Memory Measures. As in Study 1, memory measures were intercorrelated, $r=.55$ and $p<.0001$. There were no differences in performance on the memory measures based on instructions, $p s>.31$. Memory was related at trend-level to narrative transportation, $r=.17$ and $p=.09$, but neither memory measure was significantly related to any other engagement measures or manipulation check items, 
TABLE 4: Study and instructions differences in engagement, memory, and manipulation checks.

\begin{tabular}{|c|c|c|c|c|}
\hline & $\begin{array}{c}\text { Study } 1 \\
\text { mean (SD) }\end{array}$ & $\begin{array}{c}\text { Study } 2 \\
\text { overall } \\
\text { mean (SD) }\end{array}$ & $\begin{array}{c}\text { Study } 2 \\
\text { objective } \\
\text { instructions } \\
\text { condition } \\
\text { mean (SD) }\end{array}$ & $\begin{array}{c}\text { Study } 2 \\
\text { perspective-taking } \\
\text { instructions } \\
\text { condition } \\
\text { mean (SD) }\end{array}$ \\
\hline Become (direct identification) & $2.5(3.2)$ & $3.6^{*}(3.4)$ & $3.7(3.7)$ & $3.6(3.1)$ \\
\hline Narrative transportation $^{\mathrm{a}}$ & $49.5(13.9)$ & $41.5(10.5)$ & $40.9(10.5)$ & $42.5(10.3)$ \\
\hline Perceived similarity & $2.4(2.6)$ & $2.9^{*}(2.9)$ & $2.7(2.9)$ & $3.0(3.0)$ \\
\hline Wishful identification & $3.2(3.2)$ & $3.4(3.3)$ & $4.0(3.7)$ & $2.7^{*}(2.5)$ \\
\hline Free recall-total components & $8.8(4.6)$ & $11.1^{*}(4.5)$ & $11.1(4.5)$ & $11.1(5.1)$ \\
\hline Memory questions & $4.6(1.8)$ & $5.0^{+}(1.8)$ & $5.1(1.9)$ & $4.9(1.7)$ \\
\hline \multicolumn{5}{|l|}{ Study 2 manipulation check items: } \\
\hline $\begin{array}{l}\text { How much did you take the perspective of } \\
\text { the person in the story? }\end{array}$ & - & $6.2(2.7)$ & $6.5(3.4)$ & $7.4^{*}(2.2)^{b}$ \\
\hline $\begin{array}{l}\text { How much did you imagine what it would } \\
\text { be like to be the person in the story? }\end{array}$ & - & $6.1(3.3)$ & $5.6(3.6)$ & $6.8^{*}(2.8)$ \\
\hline $\begin{array}{l}\text { How much did you imagine what the } \\
\text { person in the story was thinking and feeling? }\end{array}$ & - & $6.5(3.2)$ & $5.7(3.6)$ & $7.4^{*}(2.3)$ \\
\hline
\end{tabular}

${ }^{a}$ Note that for comparison analyses, proportions were used to account for the fact that the narrative transportation measure used 8 items in Study 1 and 6 items in Study 2. Using this proportion, children reported higher narrative transportation in Study 2 than in Study $1, t(186)=3.9, p=.0001$, and $d=.56$.

${ }^{\mathrm{b}}$ Data for 10 -year-olds only because 7 -year-olds did not understand the question.

Note: differences between Study 1 and Study 2 and differences between objective and perspective-taking instructions are signified by ${ }^{*} p<.05$ and ${ }^{+} p<.10$.

nor was a memory composite related to the engagement composite, $p=.46$.

3.2.2. Primary Analyses. To determine whether children adopted character traits, we conducted regression analyses predicting each dependent variable from narrative (professor or cheerleader), instructions (perspective taking or objective), and the interaction between narrative and instructions. Models were estimated and compared as in Study 1. Controlling for gender and age group in each model did not change the pattern of results, so models without these variables are described here. Where significant effects of narrative emerged, we tested for gender $\times$ narrative and age group $\times$ Narrative interactions in order to ensure that the narrative did not differentially affect boys' and girls' and 7and 10-year-olds' behavior. Null findings in these analyses demonstrated that the narrative affected both genders and age groups similarly.

Explicit Measures. In the full model predicting children's self-ratings on the professor-relevant traits and behaviors, there was no significant interaction between narrative and instructions, interaction $B=1.9, \mathrm{SE}=2.6$, and $p=.47$, narrative $B=1.8, \mathrm{SE}=1.8$, and $p=.30$, instructions $B=-1.4, \mathrm{SE}=1.8, p=.44$, and $s r^{2}=.005$, and model $r^{2}=.05$. A simplified model showed that children who heard the professor narrative rated themselves higher on traits and behaviors associated with the professor $(\mathrm{M}=30.8, \mathrm{SD}=$ 5.9) than did children who heard the cheerleader narrative $(\mathrm{M}=28.0, \mathrm{SD}=6.9), B=2.7, \mathrm{SE}=1.3, p=.04, r^{2}=$ .043 , and model $r^{2}=.04$ (see Figure 2). Thus, children who heard the professor narrative self-reported higher levels of professor-relevant traits than children who heard the cheerleader narrative, regardless of whether they were told to take the character's perspective or to be objective. There were no significant effects of narrative or instructions or an interaction between narrative and instructions on children's self-ratings on the cheerleader-relevant traits and behaviors, interaction $B=-0.83, \mathrm{SE}=2.7, p=.76$, and $s r^{2}<.001$, model $r^{2}=.003$, narrative $B=.30, \mathrm{SE}=1.9$, and $p=$ .87 , and instructions $B=-0.28, \mathrm{SE}=1.9$, and $p=.88$. These results suggest that, at least for professor-relevant traits and behaviors, children adopted the traits of the character in the narrative. Notably, this was true for both instructions conditions, indicating that the effect holds for children who were told to take the character's perspective and for those who were told to be objective.

Implicit Measures. In the initial model predicting time playing with the analytical toy, there was not a significant interaction between narrative and instructions, interaction $B=20.0$, SE $=36.0, p=.58$, and $s r^{2}=.003$, model $r^{2}=.07$, narrative $B$ $=38.5, \mathrm{SE}=24.3$, and $p=.12$, and instructions $B=2.4$, SE $=24.4$, and $p=.92$. A simplified model showed that children who heard the professor narrative spent more time playing with the analytical toy $(M=183$ seconds, $S D=93$ seconds $)$ than children who heard the cheerleader narrative $(M=132$ seconds, $\mathrm{SD}=89$ seconds), narrative $B=50.9, \mathrm{SE}=17.7$, $p=.005$, and $r^{2}=.074$ and model $r^{2}=.07$. In the initial model predicting time spent playing with the nonanalytical toy, there was not a significant interaction between narrative and instructions, interaction $B=-11.5, \mathrm{SE}=33.4, p=.73$, $s r^{2}=.001$, and $r^{2}=.10$, narrative $B=-34.8, \mathrm{SE}=$ 22.6, and $p=.13$, and instructions $B=-29.6, \mathrm{SE}=22.6$, 


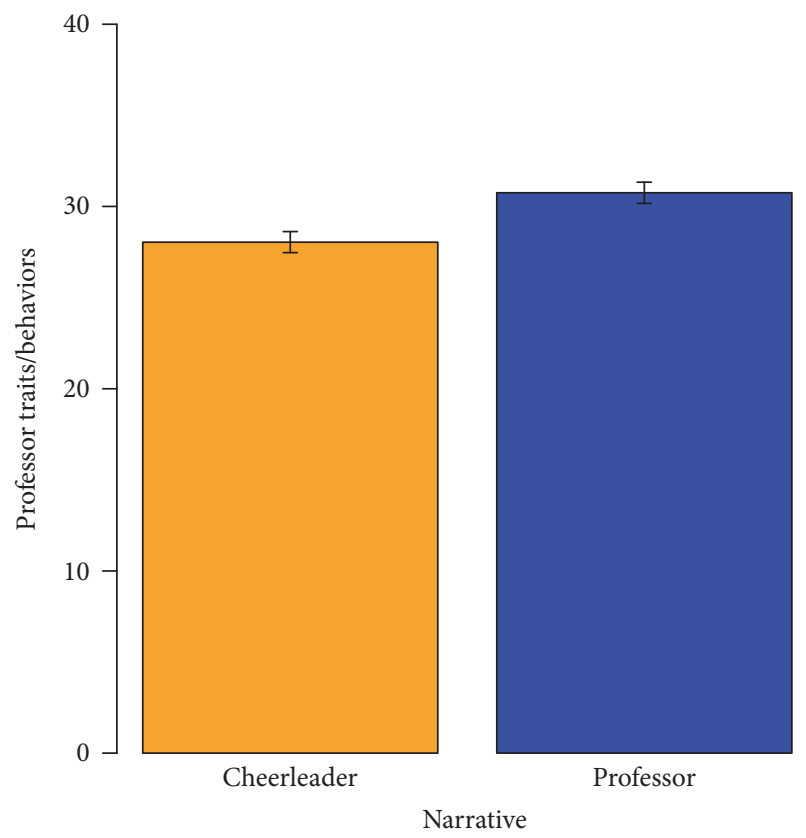

(a)

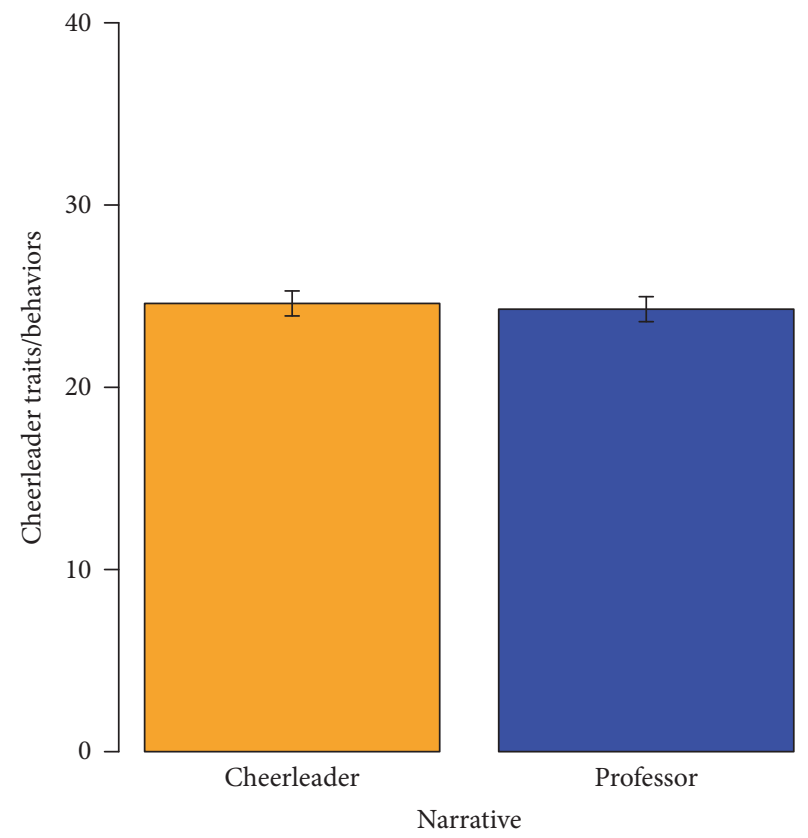

(b)

FIGURE 2: Effect of narrative on composite score of professor-relevant traits and behavior ratings (a) and composite score of cheerleaderrelevant traits and behavior ratings (b) in Study 2.

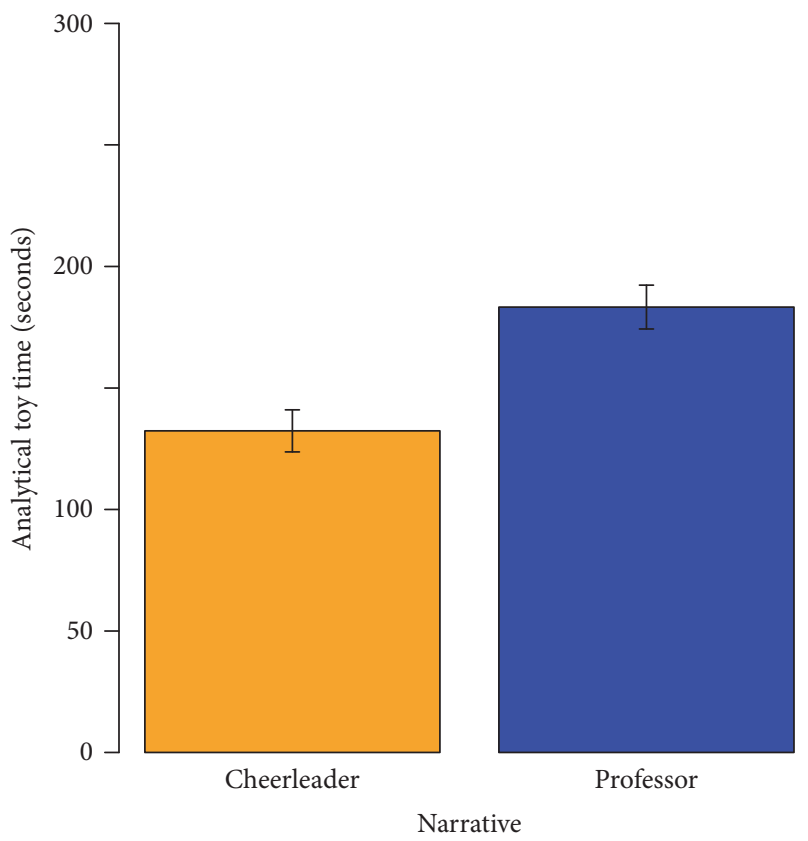

(a)

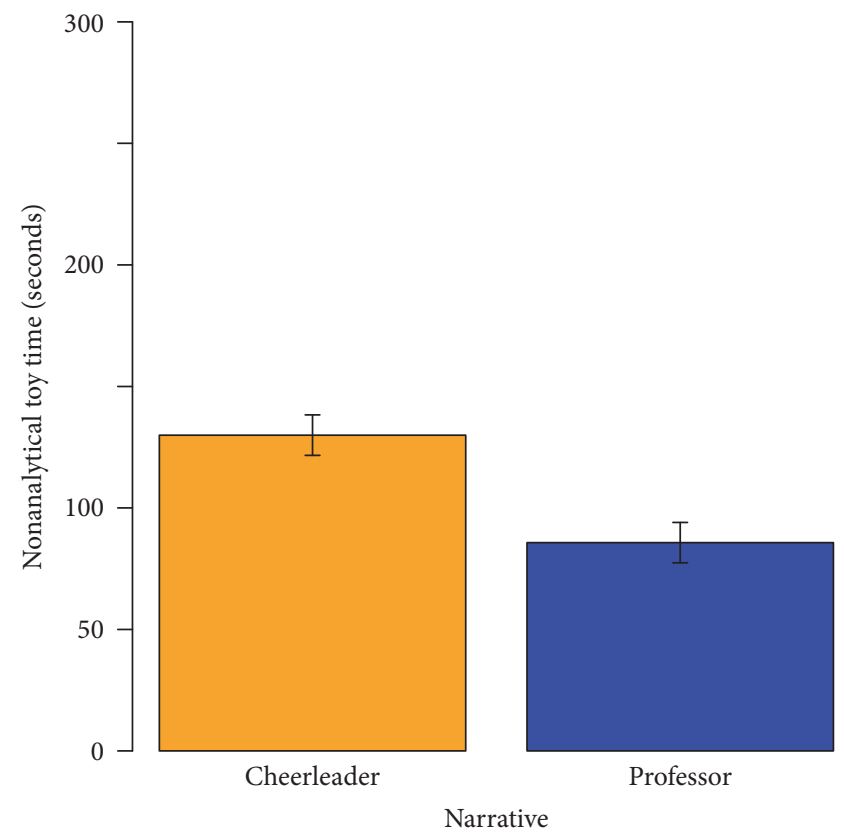

(b)

FIGURE 3: Effect of narrative on time spent playing with the analytical toy, a Rubik's cube (a), and the nonanalytical toy, a yo-yo (b), in Study 2.

and $p=.19$. A simplified model showed that children who heard the professor narrative spent less time playing with the nonanalytical toy ( $M=86$ seconds, $S D=85$ seconds $)$ than children who heard the cheerleader narrative $(M=130$ seconds, $\mathrm{SD}=85$ seconds), $B=-44.3, \mathrm{SE}=16.7, p=.01$, and $r^{2}=.064$ and model $r^{2}=.06$ (see Figure 3 ). These results suggest that children adopted the traits of the characters into their behavior and that this is true for both children who were told to take the perspective of the character and those who were told to be objective.

In a model predicting analytical reasoning score, there was no significant main effect of instructions or narrative or 
an interaction between instructions and narrative, interaction $B=-0.56, \mathrm{SE}=1.2, p=.64$, and $s r^{2}=.002$, model $r^{2}=.01$, narrative $B=.32, \mathrm{SE}=.81$, and $p=.70$, and instructions $B=.82, \mathrm{SE}=.81$, and $p=.32$, suggesting that the narrative did not affect children's analytical reasoning ability.

\subsubsection{Combined Analyses. Given the presence of main effects} of the narrative in Study 2 as opposed to the interactions with engagement seen in Study 1, we compared children's engagement and memory across studies (see Table 2). Because the engagement composite used standardized scores, individual measures of engagement were examined. Children in Study 2 differed from children in Study 1 on three measures: They reported seeing themselves as the character to a greater extent on the direct identification measure, $t(198)=2.3, p=.02$, and $d=.33$, they reported higher narrative transportation, $t(186)=3.9, p=.0001$, and $d=.56$, and they freely recalled more details from the story, $t(196)=3.6, p=.0005$, and $d=.49$. These differences held for all children, regardless of instructions. These results suggest that children in Study 2 were more engaged in the narratives compared to children in Study 1 and that this held both for children who were told to take the character's perspective and for those who were told to be objective.

3.3. Discussion. In Study 2, we attempted to manipulate perspective taking by giving children instructions to take the character's perspective or be objective while listening to the narrative. The instructions appeared effective considering the manipulation check items: Children in the perspectivetaking condition said they imagined what the character was thinking and feeling, imagined what it would be like to be the character, and took the character's perspective more than did children in the objective condition. However, even children who heard the objective instructions reported high levels of perspective taking on the manipulation check measures, rating themselves above the scale midpoint on the questions. Furthermore, expected differences between children who heard the two sets of instructions did not emerge on the four central measures of engagement. This raises the possibility that significant differences on the manipulation check items were at least partially due to children's recognition of similar wording between instructions and manipulation checks rather than to actual change in children's behavior during the narrative.

Indeed, comparing across Study 1 and Study 2 suggests children were more immersed and attentive to the story in Study 2 across both instruction conditions, as indicated in engagement and memory measures. It appears the instructions globally increased engagement and/or attention to the narratives.

Given increased engagement overall in Study 2, the main effects are consistent with Study l's interaction effects. Yet Study 2's findings are stronger, given that they occur for explicit and implicit measures, and avoid the possible confound of preexisting individual differences. In the context of increased engagement, simply hearing a narrative changed children's perceptions of their own traits and abilities as well as their behavior. This finding suggests even a brief, one-time exposure to a character in a narrative can influence children's immediate cognition and behavior, if they are highly engaged in the narrative.

Two factors might explain the unexpected global increase in engagement. One possibility is that children thought the narrative was more attention-worthy after receiving either set of instructions, because they both began with, "Now I'm going to tell you something really important." On this view, children paid more attention to the narrative after hearing the instructions, which led to higher engagement and better memory for the narrative. Another possibility is that the negative wording of the objective instructions (i.e., "Don't worry about trying to imagine what this person's life is like, how the person feels, or what it would be like to be this person") had a "White Bear" effect, such that telling children to suppress perspective taking paradoxically increased these thoughts [32]. Potentially consistent with this idea, children in the objective condition reported wanting to be like the character significantly more than children in the perspective-taking condition. Perhaps this desire emerged as a consequence of trying to inhibit the thoughts of the character.

Notably, these data cannot determine whether children adopted the professor's analytical trait, the cheerleader's nonanalytical trait, or both. On one hand, there was no effect of narrative on children's explicit self-report of cheerleaderrelevant traits and behaviors. However, it is possible that those traits (pretty/handsome, good at cartwheels) were less salient in the narrative than the professor-relevant items (smart, good at teaching) or that children's self-concepts in these areas are less malleable because they have more experience with the cheerleader-relevant activities. Regardless, hearing the cheerleader narrative could have contributed to, or even driven, the condition difference on professor-relevant items: Children who heard the cheerleader narrative may have adopted the cheerleader's nonanalytical stereotypical trait and thus rated themselves lower on the professor-relevant (analytical) items. Indeed, the interactions with engagement in Study 1 in conjunction with the current data suggest both narratives may have affected children's behavior.

An alternative explanation of these results is that children were affected by the characters' genders, adopting gendertyped traits after hearing a narrative about either a male or female character. We think this possibility is unlikely for several reasons. First, some distractor items concerned stereotypically gendered traits and behaviors; if the results reflected gender rather than profession, we would see an influence on those items. However, there were no effects on any distractor items, including stereotypically male items like "adventurous" [33], and stereotypically female items, like "cleaning" and "taking care of little kids." This finding suggests a specific effect of the analytical character, rather than a broad effect of character-gender. Furthermore, although being analytical may be associated with males, one of the items included in the professor composite was "How good are you at teaching other people?" which would presumably be more associated with females, as $87 \%$ of elementary school teachers in the USA are women [34]. However, there is an 
effect of condition on that item, again suggesting children are affected by the characters' traits rather than their gender. Nevertheless, even if characters' genders rather than characters' traits were driving the effect, this finding would still be meaningful and important. According to either explanation, children's behavior is being affected by the character they are exposed to in the narrative. Although distinct from a trait-based account, a finding showing that children act more stereotypically masculine after hearing a story about a male character and more stereotypically feminine after hearing a story about a female character would have significant implications for children's media engagement. Disambiguating these possible explanations is a task we leave to future research.

\section{General Discussion}

Our results suggest children, like adults, adopt characters' traits, particularly when highly engaged in a narrative. Specifically, in Study 2, in which all children reported high levels of engagement, children saw themselves as smarter and more competent on professor-relevant abilities and preferred playing with a toy requiring analytical skills more after hearing the professor narrative compared to after hearing the cheerleader narrative. Similar effects were present in Study 1 for children who were highly engaged. These findings are consistent with research with adults, suggesting narratives can change cognition and behavior $[1-3,5]$. The current studies are the first to extend this effect to childhood, showing at least by age 7 children are susceptible to characters' influence on cognition and behavior.

There was no evidence in these data for developmental change in this effect across the ages tested. Both 7- and 10year-olds adopted the traits of a character in a narrative despite the fact that theory of mind skills, which might be important for taking the perspective of a character, continue to improve across middle childhood. This finding is in line with previous research showing that even young children take the perspective of characters in a narrative and in their pretend play [17-19, 21-23]. Future research should investigate whether even preschoolers might also adopt characters' traits, both in a narrative context and in pretense.

Notably, the existence of this effect in childhood may be even more consequential than its adulthood equivalent. Narratives pervade children's lives: $60 \%$ of children under 8 read or are read to every day [35], whereas only $36 \%$ of adults read for pleasure daily [36], and only $55 \%$ of adults read even one book annually [37]. Beyond the frequency of narrative experiences, children are often exposed to characters repeatedly, by repeated reading of the same book or by reading many books in the same series. For example, of Amazon's Best Books of 2014 [38], 13 out of 20 books recommended for children ages 6-8 and 10 out of 20 books recommended for children ages 9-12 are parts of series. Furthermore, children's identities may be more malleable than adults', suggesting they may be more likely than adults to adopt a character's traits into their personality. In any case, these data reveal a potent effect of children's narrative exposure: Children's beliefs and behaviors are influenced in ways aligning with the traits of characters. The results also indicate that this effect is contingent on high levels of engagement.

However, these studies do not shed light on the nature of this engagement. No agreed-upon definition of perspective taking exists in the adult literature, and there is even disagreement regarding whether perspective taking or a related construct is the cognitive mechanism underpinning trait adoption. For example, Galinsky and colleagues [2] argue that perspective taking leads to trait adoption through selfother merging whereas Kaufman and Libby [5] distinguish perspective taking from "experience taking" or identification. Moreover, narrative transportation also leads to adoption of characters' traits [4]. In Study 1, we used engagement measures theoretically assessing narrative transportation and experience taking, which related to trait adoption. In Study 2, we additionally used instructions intending to alter perspective taking and neither related to trait adoption, presumably due to elevated engagement. Thus, it is unclear which aspects of engagement may have driven our effects.

A second challenge lies in translating these constructs into childhood and adapting measures for children. Even careful adaptation of established measures from the adult literature does not ensure children's interpretation of items aligns with adults'; substantially different measures may be needed to assess the same concept in childhood. However, our results suggest these measures have construct and predictive validity in an adapted form with children. Future research should investigate more objective ways to assess these constructs, perhaps through reaction-time or brain activity measures.

A limitation of the current studies is that we assessed a one-time, immediate effect. Thus, it is possible the effects are ephemeral. After hearing the narrative, however, children completed a 5-minute filler task and scale training (between 1.5 and 2 minutes) prior to beginning the trait adoption tasks. Hence, trait adoption is sustained for at least some time after exposure. Furthermore, as mentioned earlier, children's exposure to characters is often frequent and repeated. Thus, even if one exposure did not yield long-term effects, cumulative effects may accrue over time. There may also be cascading effects: If a child spends more time playing with an analytical toy after adopting the traits of a professor character, they may change their beliefs or attitudes about themselves to align with their own observed behavior [39]. However, it will be valuable for future research to investigate the longevity of these effects.

The current studies could also underestimate the strength and robustness of the effects of narratives on children's trait adoption. We found that a 2.5-minute narrative substantially influenced cognition and behavior, so given that children are usually exposed to longer narratives the real-world effects could be stronger. Also, because the narratives used here were adapted from research with adults, they were not especially exciting or relevant to our sample. If, as these studies suggest, engagement in and attention to the narrative are important factors in trait adoption effects, children may be more likely to be influenced by narratives targeted towards their age group and interests, like those they seek out and are more likely exposed to in their everyday lives. Further research should 
examine whether effects are stronger with longer exposure and age-targeted narratives.

Another important area for future research is investigating and comparing engagement in and effects of narratives across media. Theoretically, trait adoption effects should be seen across media, but some types may facilitate higher engagement and/or higher involvement with the character, thereby leading to stronger effects. In the current studies, we used a short audio recording, and results may differ using storybooks, novels, or television or video-based narratives. One limitation of the current study is that this format is an unusual way for children to engage with a narrative; future research should investigate more ecologically valid narrative mediums. However, it is also possible using the unusual audio format may have weakened effects that would be stronger when children are exposed to narratives in more familiar formats.

Regardless of the medium through which children were exposed to the narrative in the current study, it is not clear whether children interpreted the narrative as fictional or nonfictional. Although the narratives were, in fact, fictional, children were simply told that they would listen to a recording about a person, and the images of the characters were realistic photographs. Future research could more specifically label narratives as fictional or nonfictional to determine whether such labeling influences children's trait adoption.

Finally, future work is needed to probe the generalization of this effect to other traits. Here, we showed effects on analytical self-concept and behavior. Although we see no reason trait adoption should be confined to this trait, it will be important for further studies to extend this finding to other traits and behaviors. Furthermore, these data cannot disambiguate whether effects are due to characteristics of the protagonist specifically or whether the differing settings and themes of the story would be sufficient. It will be important for future research to assess the effects of these aspects separately.

Overall, our results suggest narratives can have immediate and consequential effects on children's real-world cognition and behavior. Specifically, these studies show that children who became engaged in a narrative subsequently adopted some of the central character's traits. More broadly, these data contribute to our growing knowledge of the nature and effects of children's engagement with narratives.

These findings have implications for the creation of children's media and for the choices parents and teachers make about children's narrative exposure. The trait adoption effect could be capitalized upon to promote positive outcomes for children. Children might also adopt a character's kind attitudes, healthy behavior, or ambitious goals. Future research should investigate possible applications of these findings in order to use narratives to positively affect children's lives.

\section{Appendix}

\section{A. Professor and Cheerleader Narratives}

A.1. Professor Narrative. "Okay. So you want me to describe a normal day in my life as a professor. My name is Keith and
I am a professor in the Biology Dept. at a university. Last Friday was a pretty normal day. I got up early to make my two kids breakfast, they really like French toast. I then left for the office. I was feeling really tired because I had been up late getting ready to teach my class on the human body. But at the same time I was really excited about teaching the class that day because I found this particular topic, which was on the relationship between foods we eat and our health, to be very interesting. In fact, I was most excited because the topic I was going to be teaching on had the opportunity to help my research ideas. In my research, I do studies in a lab to find out more about the human body. Doing very good research is an important part of making sure I can keep my job as a professor for as long as I want. I am an assistant professor now, which means I need to be promoted before I can keep my job as long as I want. In order to be promoted, I need to work very hard on research questions that interest me. Getting promoted at my university is certainly not an easy thing to do. My research has been going well but I really need to have a home run. A home run is what I call a paper that changes the way other professors around the country think about a problem. I am hoping to impact Biology by looking at how certain foods people eat change the energy cycles in their body and then result in healthy or unhealthy eating later. So class went really well that day and I was super excited. I had lunch with another professor who always seems to think my ideas are terrible but he seemed to like what I had to say that day. The afternoon was filled with a very boring meeting with other professors that went on and on-I think it lasted something like 3 hours! I met a friend for a game of tennis-we meet every week and it is great fun because we are both good at tennis. That night I was supposed to make dinner, but I did not feel like cooking so I ordered out for pizza; my wife was not very happy and reminded me that I often do not eat very healthy. After dinner, I spent some time trying to find a babysitter for this weekend so that my wife and I could go see a new movie. After helping my kids with their homework, I spent the last few hours of the evening working on reading a friend's book and writing up a report on it."

A.2. Cheerleader Narrative. "Okay. So you want me to describe a normal day in my life as a cheerleader. My name is Kelly and I am a cheerleader on my high school cheerleading team. Last Friday was a pretty normal day. I was feeling really tired because I had gotten up early to do my hair, paint my nails, and plan my outfit for school that day. But at the same time I was really excited because I was going to wear the new skirt I got from a cool store at the mall. In fact, I was most excited because by carefully planning out this new outfit I had the chance to show everyone that I'm one of the prettiest girls in the school. Dressing really nice and making sure you look good is almost as important as your cheerleading skills in deciding who will be asked to be the captain of the team next year. I've been on the cheerleading team for three years and I really want to be team captain, which means that the coaches need to think I am a really good cheerleader. In order to be asked to be the captain, I need to practice my cheers and routines and be really good at them. My cheers and routines are pretty good now, but what I really need to have 
is a home run. A home run is what I call a complicated cheer routine that I can do perfectly - one that will really impress the coaches. I am hoping to impress the varsity cheerleading coach with my double back flip stunt and by having our new cheers perfectly memorized so I can focus on shouting them really loudly. So after my morning classes that day, I had lunch with another cheerleader who always seems to think my cheer ideas are terrible but she seemed to like them that day. The afternoon was filled with boring classes that went on and on. After school, I went to cheer practice - we meet every day and it is great fun because we are all very good at cheering and doing stunts. That night I ate dinner with my mom and dad. My dad was going to make dinner but he got home late, so we ordered pizza instead. After dinner, I did my homework and then spent some time looking through new colors of nail polish on the Internet. I hope the makeup store in the mall has the colors I found on the website! They would match my cheerleading uniform perfectly. I spent the last few hours of the evening working on my cheers for the weekend football game."

\section{B. Trait and Behavior Rating Items}

\section{B.1. Traits}

Smart

Pretty or handsome

Adventurous

Good

Hungry

Calm

Patient

Tired

Funny

\section{B.2. Behaviors}

How good are you at shouting loudly?

How good are you at setting the table?

How good are you at teaching other people?

How good are you at taking care of little kids?

How good are you at doing cartwheels?

How good are you at coming up with new ideas?

How good are you at cleaning?

How good are you at playing cards?

How long can you concentrate while thinking about something?

How good are you at drawing?

How high can you jump?

How good are you at making pizza?
TABLE 5: Correlation table for predictor variables in Study 1.

\begin{tabular}{|c|c|c|c|c|c|}
\hline & 1 & 2 & 3 & 4 & 5 \\
\hline $\begin{array}{l}\text { (1) Narrative } \\
\text { Transportation } \\
\text { Scale }\end{array}$ & & & & & \\
\hline $\begin{array}{l}\text { (2) Perceived } \\
\text { similarity }\end{array}$ & $.27^{*}$ & & & & \\
\hline $\begin{array}{l}\text { (3) Wishful } \\
\text { identification }\end{array}$ & $.21^{*}$ & $.50^{*}$ & & & \\
\hline $\begin{array}{l}\text { (4) Direct measure } \\
\text { of identification }\end{array}$ & $.41^{*}$ & $.43^{*}$ & $.33^{*}$ & & \\
\hline $\begin{array}{l}\text { (5) Number of } \\
\text { details freely } \\
\text { recalled }\end{array}$ & -.02 & .05 & .06 & -.002 & \\
\hline $\begin{array}{l}\text { (6) Number of } \\
\text { memory questions } \\
\text { answered correctly }\end{array}$ & .02 & -.06 & .09 & .09 & $.60^{*}$ \\
\hline
\end{tabular}

\section{Narrative Transportation Scale Items}

(1) While you were listening to the recording, you could easily picture the events happening.

(2) While you were listening to the recording, you were paying attention to things in this room around you [reverse scored].

(3) You could picture yourself in the scene of the events that happened in the recording.

(4) You were really thinking about the recording while you were listening to it.

(5) After the recording was over, you stopped thinking about it [reverse scored].

(6) You wanted to find out what happened to the person in the recording.

(7) The recording made you feel either happy or sad.

(8) You started thinking about other things while you were listening to the recording [reverse scored].

(9) You could really picture the person that you heard about in the recording.

\section{Correlation Table for Predictor Variables in Study 1}

See Table 5.

\section{E. Correlation Table for Predictor Variables in Study 2}

See Table 6.

\section{Additional Points}

Rebecca Dore is now at University of Delaware. Eric Smith is now at University of Arizona. 
TABLE 6: Correlation table for predictor variables in Study 2.

\begin{tabular}{|c|c|c|c|c|c|}
\hline & 1 & 2 & 3 & 4 & 5 \\
\hline \multicolumn{6}{|l|}{$\begin{array}{l}\text { (1) Narrative } \\
\text { Transportation } \\
\text { Scale }\end{array}$} \\
\hline $\begin{array}{l}\text { (2) Perceived } \\
\text { similarity }\end{array}$ & .04 & & & & \\
\hline $\begin{array}{l}\text { (3) Wishful } \\
\text { identification }\end{array}$ & .02 & $.29^{*}$ & & & \\
\hline $\begin{array}{l}\text { (4) Direct measure } \\
\text { of identification }\end{array}$ & $.36^{*}$ & $.27^{*}$ & $.27^{*}$ & & \\
\hline $\begin{array}{l}\text { (5) Number of } \\
\text { details freely } \\
\text { recalled }\end{array}$ & .11 & -.01 & -.02 & .09 & \\
\hline $\begin{array}{l}\text { (6) Number of } \\
\text { memory questions } \\
\text { answered correctly }\end{array}$ & $.17^{+}$ & -.06 & .03 & .06 & $.55^{*}$ \\
\hline
\end{tabular}

\section{Competing Interests}

The authors declare that they have no competing interests.

\section{Acknowledgments}

This research was supported by National Science Foundation Grant no. 1024293, Sir John Templeton Foundation Grant 56225, a Brady Education Foundation grant to Angeline S. Lillard, a National Science Foundation Graduate Research Fellowship Grant to Eric D. Smith, and an IES postdoctoral training grant supporting fellow Rebecca A. Dore. Many thanks are due to all the families and children who participated in this research and to Hillary Keach, Virginia Bell, Andrea Yuly, Liz Hasseltine, Russel Houser, and Kimberly Cummings for their assistance in data collection and coding. Special thanks are due to Jeff Dore and Ashley Bozarth for providing the voice recordings.

\section{References}

[1] S. Gabriel and A. F. Young, "Becoming a vampire without being bitten: the narrative collective-assimilation hypothesis," Psychological Science, vol. 22, no. 8, pp. 990-994, 2011.

[2] A. D. Galinsky, C. S. Wang, and G. Ku, "Perspective-takers behave more stereotypically," Journal of Personality and Social Psychology, vol. 95, no. 2, pp. 404-419, 2008.

[3] S. C. Wheeler, W. B. G. Jarvis, and R. E. Petty, "Think Unto Others: the self-destructive impact of negative racial stereotypes," Journal of Experimental Social Psychology, vol. 37, no. 2, pp. 173180, 2001.

[4] M. A. Sestir and M. C. Green, "You are who you watch: identification and transportation effects on temporary selfconcept," Social Influence, vol. 5, no. 4, pp. 272-288, 2010.

[5] G. F. Kaufman and L. K. Libby, "Changing beliefs and behavior through experience-taking," Journal of Personality and Social Psychology, vol. 103, no. 1, pp. 1-19, 2012.
[6] T. Bravender, A. Russell, R. J. Chung, and S. C. Armstrong, "A 'novel' intervention: a pilot study of children's literature and healthy lifestyles," Pediatrics, vol. 125, no. 3, pp. e513-e517, 2010.

[7] L. K. Fazio and E. J. Marsh, "Older, not younger, children learn more false facts from stories," Cognition, vol. 106, no. 2, pp. 10811089, 2008.

[8] N. Emmons, H. Smith, and D. Kelemen, "Changing minds with the story of adaptation: strategies for teaching young children about natural selection," Early Education and Development, vol. 27, no. 8, pp. 1205-1221, 2016.

[9] D. Kelemen, N. A. Emmons, R. S. Schillaci, and P. A. Ganea, "Young children can be taught basic natural selection using a picture-storybook intervention," Psychological Science, vol. 25, no. 4, pp. 893-902, 2014.

[10] A. Shtulman, C. Neal, and G. Lindquist, "Children's ability to learn evolutionary explanations for biological adaptation," Early Education and Development, pp. 1-15, 2016.

[11] R. A. Richert, A. B. Shawber, R. E. Hoffman, and M. Taylor, "Learning from fantasy and real characters in preschool and kindergarten," Journal of Cognition and Development, vol. 10, no. 1-2, pp. 41-66, 2009.

[12] R. A. Richert and E. I. Smith, "Preschoolers' quarantining of fantasy stories," Child Development, vol. 82, no. 4, pp. 1106-1119, 2011.

[13] C. M. Walker, A. Gopnik, and P. A. Ganea, "Learning to learn from stories: children's developing sensitivity to the causal structure of fictional worlds," Child Development, vol. 86, no. 1, pp. 310-318, 2015.

[14] R. T. Devine and C. Hughes, "Silent films and strange stories: theory of mind, gender, and social experiences in middle childhood," Child Development, vol. 84, no. 3, pp. 989-1003, 2013.

[15] A. E. O’Hare, L. Bremner, M. Nash, F. G. E. Happé, and L. M. Pettigrew, "A clinical assessment tool for advanced theory of mind performance in 5 to 12 year olds," Journal of Autism and Developmental Disorders, vol. 39, no. 6, pp. 916-928, 2009.

[16] I. A. Apperly, F. Warren, B. J. Andrews, J. Grant, and S. Todd, "Developmental continuity in theory of mind: Speed and accuracy of belief-desire reasoning in children and adults," Child Development, vol. 82, no. 5, pp. 1691-1703, 2011.

[17] D. G. Singer and J. L. Singer, The House of Make-Believe: Children's Play and the Developing Imagination, Harvard University Press, Cambridge, Mass, USA, 1990.

[18] E. D. Smith and A. S. Lillard, "Play on: retrospective reports of the persistence of pretend play into middle childhood," Journal of Cognition and Development, vol. 13, no. 4, pp. 524-549, 2012.

[19] P. L. Harris, "Role play," in The Work of the Imagination, WileyBlackwell, Malden, Mass, USA, 2000.

[20] M. C. Green and T. C. Brock, "The role of transportation in the persuasiveness of public narratives," Journal of Personality and Social Psychology, vol. 79, no. 5, pp. 701-721, 2000.

[21] D. K. O’Neill and R. M. Shultis, “The emergence of the ability to track a character's mental perspective in narrative," Developmental Psychology, vol. 43, no. 4, pp. 1032-1037, 2007.

[22] J. Rall and P. L. Harris, "In Cinderella's slippers? Story comprehension from the protagonist's point of view," Developmental Psychology, vol. 36, no. 2, pp. 202-208, 2000.

[23] F. Ziegler, P. Mitchell, and G. Currie, "How does narrative cue children's perspective taking?" Developmental Psychology, vol. 41, no. 1, pp. 115-123, 2005. 
[24] K. Lee, V. Talwar, A. McCarthy, I. Ross, A. Evans, and C. Arruda, "Can classic moral stories promote honesty in children?" Psychological Science, vol. 25, no. 8, pp. 1630-1636, 2014.

[25] R. Tukachinsky, "Experimental manipulation of psychological involvement with media," Communication Methods and Measures, vol. 8, no. 1, pp. 1-33, 2014.

[26] S. J. Rowley, B. Kurtz-Costes, R. Mistry, and L. Feagans, "Social status as a predictor of race and gender stereotypes in late childhood and early adolescence," Social Development, vol. 16, no. 1, pp. 150-168, 2007.

[27] D. Weschler, The Weschler Intelligence Scale for Children, Psychological Corporation, San Antonio, Tex, USA, 4th edition, 2003.

[28] C. Hoffner, "Children's wishful identification and parasocial interaction with favorite television characters," Journal of Broadcasting and Electronic Media, vol. 40, no. 3, pp. 389-402, 1996.

[29] P. E. Jose and W. F. Brewer, "Development of story liking: character identification, suspense, and outcome resolution," Developmental Psychology, vol. 20, no. 5, pp. 911-924, 1984.

[30] R Development Core Team, R: A Language and Environment for Statistical Computing, R Foundation for Statistical Computing, Vienna, Austria, 2014.

[31] D. R. Anderson, Model Based Inference in the Life Sciences: A Primer on Evidence, Springer, New York, NY, USA, 2008.

[32] D. M. Wegner, D. J. Schneider, S. R. Carter, and T. L. White, "Paradoxical effects of thought suppression," Journal of Personality and Social Psychology, vol. 53, no. 1, pp. 5-13, 1987.

[33] R. S. Bigler, "The role of classification skill in moderating environmental influences on children's gender stereotyping: a study of the functional use of gender in the classroom," Child Development, vol. 66, no. 4, pp. 1072-1087, 1995.

[34] OECD, Education at a Glance 2014: OECD Indicators, OECD Indicators, OECD Publishing, Paris, France, 2014.

[35] Common Sense Media, “Zero to eight: children's media use in America," 2013, https://www.commonsensemedia.org/ research/zero-to-eight-childrens-media-use-in-america-2013.

[36] Pew Research Center, The rise of e-reading, http://libraries .pewinternet.org/files/legacy-pdf/The\%20rise $\% 20$ of\%20ereading\%204.5.12.pdf.

[37] National Endowment for the Arts, "How a nation engages with art: highlights from the 2012 survey of public participation in the arts," https://www.arts.gov/sites/default/files/ highlights-from-2012-sppa-revised-oct-2015.pdf.

[38] Best Children's Books of 2014, http://www.amazon.com/b/ref= amb_link_426357402_3?ie=UTF8\&node $=10207133011 \& p f \_r d$ $\mathrm{m}=$ ATVPDKIKX0DER\&pf_rd_s=merchandised-search leftnav\&pf_rd_r=19KAC98Y7VNAGDY7T2EJ\&pf_rd_t=101\&pf_ rd_p=1968735602\&pf_rd_i=10207069011http://www.amazon .com/b/ref=amb_link_4263574.

[39] D. J. Bem, "Self-perception theory," in Advances in Experimental Social Psychology, vol. 6 of Advances in Experimental Social Psychology, pp. 1-62, Academic Press, New York, NY, USA, 1972. 


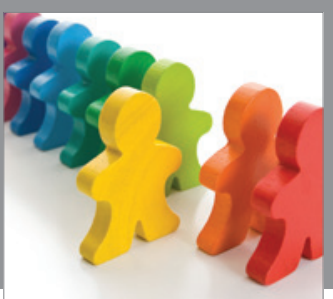

Autism

Research and Treatment
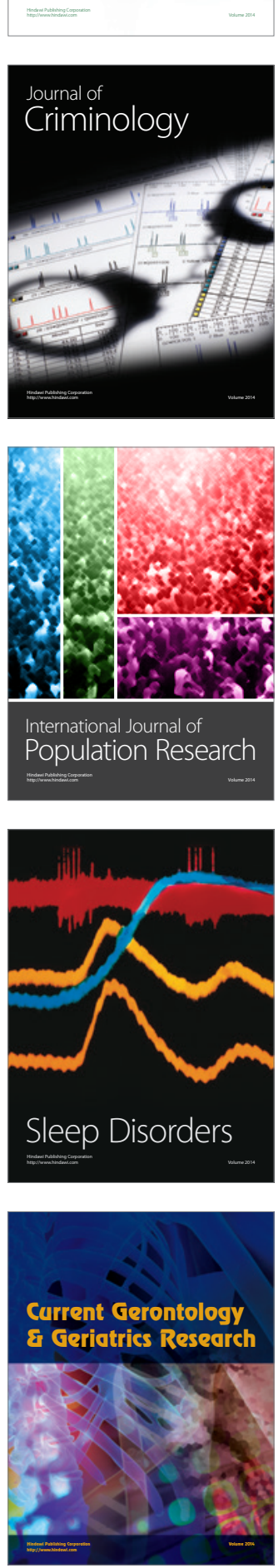

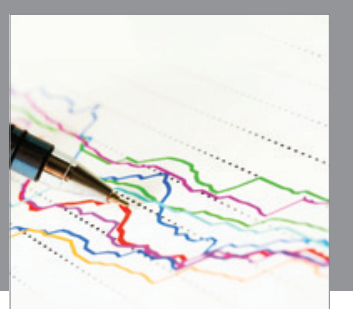

Economics

Research International
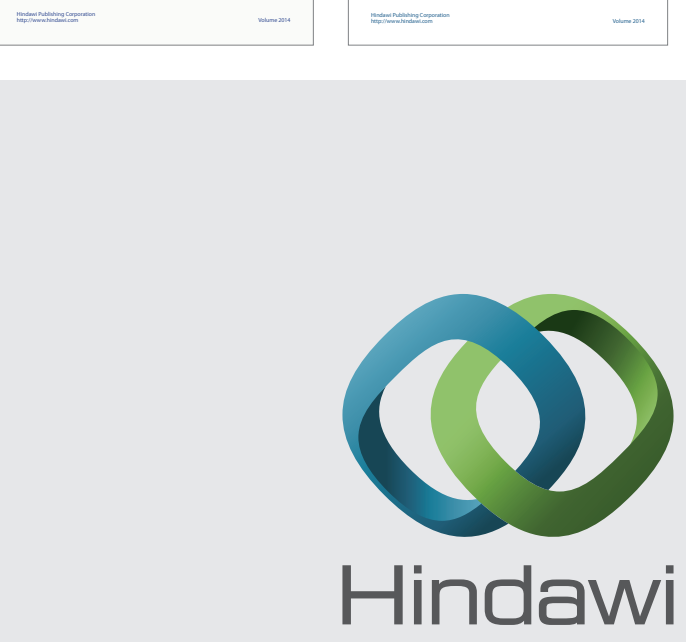

Submit your manuscripts at

https://www.hindawi.com
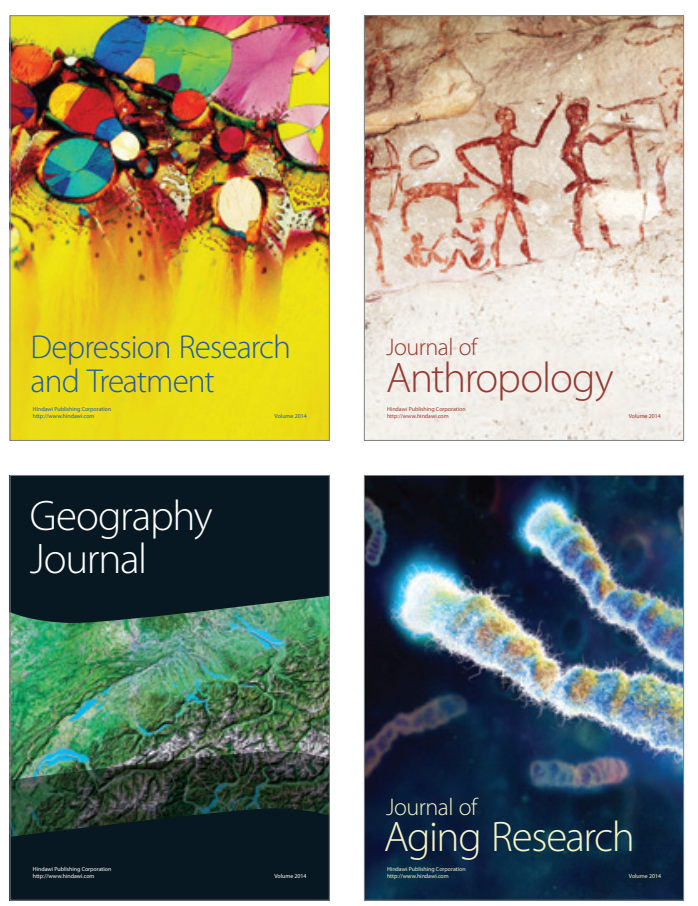
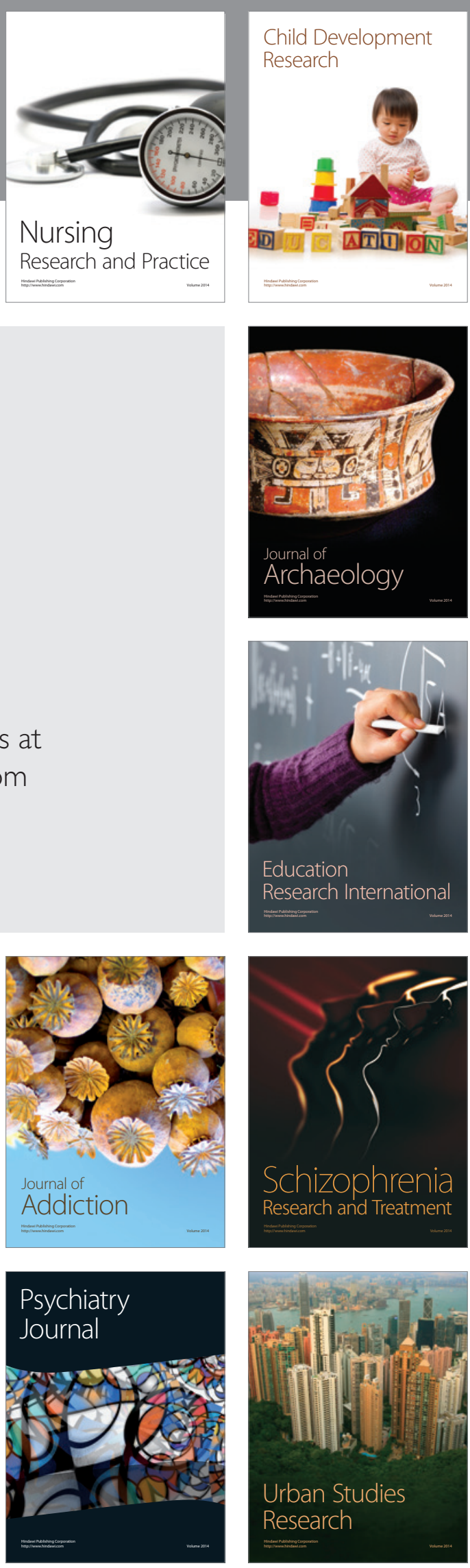